\title{
Defining a Method of Evaluating Die Life Performance by Using Finite Element Models (FEM) and a Practical Open Die Hot Forging Method
}

\author{
J. Marashi ${ }^{1, a}$, J. Foster ${ }^{2, b}$, R. Zante ${ }^{2, c}$ \\ ${ }^{1}$ DMEM University of Strathclyde ${ }^{2}$ Advanced Forming Research Centre \\ ajames.marashi@strath.ac.uk,bjim.foster@strath.ac.uk,'remi.zante@strath.ac.uk
}

\begin{abstract}
Die wear, which is defined as a surface damage or re moval of material from one or both of two solid surfaces in a sliding, rolling or impact motion relative to one a nother, is considered the main cause of tool failure. Wear is responsible for $70 \%$ of tool failure and a potential source of high costs; as much as $30 \%$ perforging unit in the forging industries [1]. This paper presents a unique wear prediction and measurement methodforopen die forging using a modified Archard equation, 3D FE simulation (to represent the actual forging process precisely) and an industrial scale forging trial. The proposed tool and experimental design is aimed at facilitating a cost effective method of tool wear a nalysis and to establish a repeatable method of measure ment. It creates a platform to test different type of lubricants and coatings on indus trial scale environment. The forging trial was ca rried out using 2100T Schuler Screw press. A full factorial experiment design was us ed on 3D simulation to identify the process setting for creating a measurable amount of tool wear. Wear prediction of $28.5 \mu \mathrm{m}$ bas ed on the simulation correlated with both Infinite Focus Optical Microscope and Coordinate Measuring Machine (CMM) measure ment re sults of the practical trial. Thermal ca mera reading showed te mperature raise o $n$ the a rea with maximum wear, which suggests that increase in contact time, causes thermal softening on tool steel. The mea surement showed that a brasive wear and adhesive wear a re dominant failure modes on the tool under these process conditions.
\end{abstract}

\section{INTRODUCTION AND BACKGROUND}

Forging technology has a special place in production lines because of the ability to produce relatively complex parts with excellent mechanical properties and the minimum possible waste. However, expensive tooling makes forging more attractive when high production levels of parts or mechanical properties are required for finished parts, which can only be achieved using forging [1].

The cost of material, energy and manpower is rising every year and this makes the forging industry minimise costs while product integrity stays the same. Industries are therefore attracted to computer aided technology, especially FEA and FVA analysis, which are cost effective compared to trial and error experiments. However, lengthy computer time forces researchers to use 2D simulation instea d of 3D simulation, which is possible for axisymmetric geometries but it makes sense to be compared with a 3D model to maintain the integrity of the results. The geometry which is being used in this project is not axisymmetric, meaning that using a $2 \mathrm{D}$ simulation is not possible. As forging technology is being used because of the ability to produce relatively complex parts with excellent mechanical properties, the author will argue whether any $2 \mathrm{D}$ simulation maintains the integrity of the results of the forging process, especially when simulation is used to predict die life. Furthermore, 3D simulation would allow overlaying geometries before and after forging, increasing the accuracy of measurement.

Die wear prediction is another area in which industries are interested because wear is responsible for $70 \%$ of tool failure and a potential source of high costs; as much as $30 \%$ per forging unit in the forging industries. Tool wear is the result of motion of components relative to adjacent parts, which results in material loss on the surface. It is the almost inevitable companion of friction and, if two surfaces rub together without any lubricant, their friction increases immensely. This increases the wear in close dieforging but this is not the case in open die forging [1]. Wear is damage which progresses gradually[2]. Wear depends on a number of factors that cannot be prevented. Nonetheless, it can be minimised by choosing the right material with the correct hardness and by using, for example, the proper heating and descaling. When two solid bodies are brought into loaded contact, the stresses developed within each of them may either be entirely elastic or sufficiently large for the yield criterion for plastic deformation to be exceeded within one, or possibly both. If the deformation is such that elastic stress fields are predominant, in the case of metals (for which the elastic moduli are high), the strains must be correspondingly small and the theory of linear elasticity can be applied. 
Overheating could be considered as another factor in die failure as, in hot and warm forging, dies are heated to $230-250^{\circ} \mathrm{C}$ temperatures. However, if such temperatures have not been set properly, this can decrease the resistance of the die towards wear or cause die checking and thermal fatigue [3]. Many researchers have attempted to predict wear. Vardan et al [4] estimated die wear during upsetting and hot forging on the basis of finite element analyses and investigated the effects of process variables on die wear, finding that temperature and sliding velocity (distance for a given stroke rate) had the greatest effect on die wear.

The correlation between prediction and experiment was very good for cold and warm upsetting but not for hot upsetting,Milan Terčelj, who came up with a combination of the FEM and the condition average estimator (CAE NN) to predict wear [5], their experimetns was in lab scale and not an industrial scale.Tulsyan et al and Painter et al [6], investigated the use of the finite element code Deform, together with a post-processing code, to predict die wear in extrusion of automotive exhaust valves.their approach gave a trend of wear for close die forging However they failed to consider the effect of parameters like lubricant and they didn't consider tool hardness to be temperature dependance. Lee and IM[7] implemented Archard's wear model to a finite element programme for calculating wear profiles in dies and compared the numerically obtained wear profiles to available experimental results, they assumed that tool wear will be simmilar in each blow which is not the case in real life. Therefore a modified Tulsyan et al. and Painter et al. Archard formula was used for this project, considering the hardness function of temperature (1),

$$
W=K \int \frac{U^{a} P^{b}}{H(T)^{c}} d t
$$

Where $\mathrm{W}=$ Wear depth, $\mathrm{K}=$ Dimensionless wear coefficient (experimentally defined), $\mathrm{U}=$ Sliding velocity, $\mathrm{P}=$ Interface pressure, $\mathrm{H}=$ Tool hardness function of temperature, $(\mathrm{a}=1, \mathrm{~b}=1, \mathrm{c}=2)$ experimental values. Archard considered wear coefficient, sliding velocity, load or contact pressure, tool hardness and contact time as the main parameters involved in producing tool wear. Other parameters like lubricants was considered to be critial in this project and muliple cycle simulations and forging trials was executed to represent the real life forging . other parameters such as die design, selection of die material, type of surface tribology (lubrication and tool coating materials being used), type of press and shape size of the part are critical for increasing die life [8].

$\mathrm{H} 13$ tool steel was selected for this project with hardness of 53HRC. H13 chemical composition makes it suitable for hot forging. It has the second highest percentage of chromium compared to the rest of the $\mathrm{H}$ series .Chromium has good wear resistance properties [9] Molybdenum does not visibly react with oxygen or water at room temperature and Vanadium can enhance the strength, as well as the toughness and plasticity, of steel and improves fabrication and service performance. [10].

Hot forging dies are put under harsh process conditions. The rapid change of temperature causes tools to wear quicker. Having a thermal camera for this project was therefore necessary to monitor any thermal changes during the forging process.

\section{RESEARCH PLAN}

The research plan was to model a four pieces die set, including upper and lower die, insert and end stop FIGURE 1,. The insert was designed with a specific angle to increase the sliding and shear stress on the tool. The insert creates a notch on the billet and, while the billet slides on the tool, it wears the tool surface. Using insert instead of full die block is reduces the material usage and easy to replace which is efficient and cost effective. Full factorial design of experiments on the DEFORM 3D simulation software defines process settings. DEFORM 3D software is capable of calculating wear depth using equation (1) and it considered more reliable for this process. Predicted wear could be validated by a practical forging trial.

The plan for the practical trial was to forge 100 of 321 stainless steel billets on $\mathrm{H} 13$ tool steel. A Land Instruments ARC Infrared Thermal Imaging Camera can capture thermal changes during the process. Water based lubricant with around $10 \%$ of graphite solids content considered a suitable lubricant. For post processing Optical Microscope and $\mathrm{CMM}$ was selected to scan the insert before and after the forging process which could be overlaid using GOM software. This is explained in the measurement method section of this paper. 


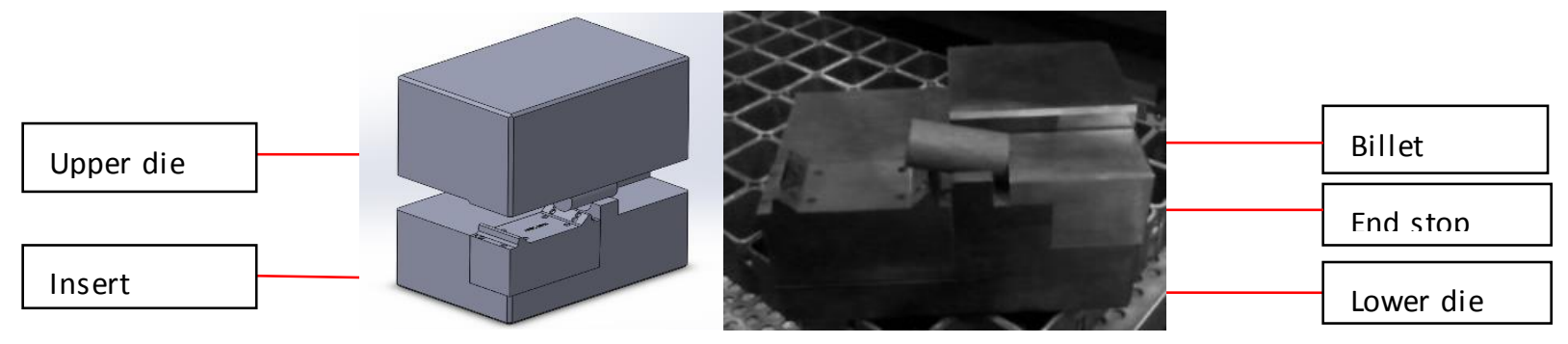

FIGURE 1. Die Set

\section{USING FINITE ELEMENT SIMULATION TO PREDICT DIE WEAR}

A three dimensional FE model was used to simulate the non-isothermal open die hot forging process. An Implicit Lagrangian Incremental scheme was used for time integration. A five pieces rigid-plastic model was used for calculating wear, considering four pieces rigid die and a plastic billet. For taking heat transfer under consideration as one of the main causes of tool wear the die and work piece were meshed, considering smaller mesh sizes on the contact area.

Materials data were taken from the Deform 3D data base. A small size tetrahedral mesh was used for the billet and dies to maximise accuracy. Energy, moment of inertia and other crucial inputs for the screw press were entered based on the screw press model used at the AFRC facilities The modified Archard formula (1), was used, which is an existing model in the FE software data base. The wear coefficient $\mathrm{K}$ was considered to be $1 \times 10^{-6}$ when lubricant was applied and $1500 \times 10^{-6}$ when lubricant was not applied [11]. Values for a,b,c were considered to be 1,1,2 for steel. A friction coefficient of 0.3 was used for the lubricated simulation and friction of 0.7 was used for dry simulation. Values for tool hardness were taken from the literature for different temperatures [12].

To investigate the stress on the tool steel at high temperature and to find out if tools were going to deform under trial conditions, further simulation was carried out using an elastic insert. All other settings were considered exactly like a previous rigid model.

\section{RUNNING A FULL FACTORIAL DESIGN OF EXPERIMENT}

A full factorial design of experiments was used on simulation using Minitab software to find the best process parameters for maximising wear in initial forging trials. As mentioned earlier, this is to create a measurable amount of wear, which can be measured using existed facilities within the centre. Variables were considered to be billet temperature (3 levels), energy on screw press (3 levels) and with or without lubricant (2 levels)TABLE 1. These variables have a direct effect on hardness, interface pressure and sliding velocity. These are the main parameters on the Archard formula (1), which is embedded in 3D FE software for calculating wear. The result showed that $10 \%$ of energy on the screw press, a $950^{\circ} \mathrm{C}$ billet temperature and us e of lubricant could create a measurable amount of wear. Wear increases in open die forging by using lubricant because of increase in sliding [4]. After finding the process setting, a multiple cycle simulation was run to see the nature of wear progression.

TABLE 1.Full Factorial Design of experiments variables (Billet $\mathrm{T}{ }^{\circ} \mathrm{C}, \%$ Energy on Screw press, Lubricant)

\begin{tabular}{|c|c|c|}
\hline Billet Temprature ${ }^{\mathbf{0}} \mathbf{C}$ (3 Levels) & \% Energy on Screw press (3 levels) & Lubricant(2 Levels) \\
\hline 950 & 5 & Yes \\
\hline 1050 & 10 & No \\
\hline 1150 & 15 & \\
\hline
\end{tabular}

\section{Open Die Forging Practical Trial}

The practical trial was conducted using a 2100TSchuler industrial scalescrew press to forge 100 billets of stainless steel (321grade) on tool steel $(\mathrm{H} 13)$. The process setting was set at $10 \%$ of energy on the screw press and a $950^{\circ} \mathrm{C}$ billet temperature. Water based graphite lubricant was used as a lubricant. The furnace was heated up to $950^{\circ} \mathrm{C}$ and 36 billets were placed into the furnace, which was heated up and forged in sequence. The forging process was 
undertaken manually, meaning that contact time could not be fixed, which will be explained in detail. The thermal camera was used to capture the change in temperature during the forging process. This could also be used to monitor a variation in contact time. The emissivity of 0.7 was considered for the reading because there was not any trace of lubricant on the selected area.

\section{MEASUREMENT METHOD}

For measuring wear depth on a DEFORM 3D post-processor, 500 points with equal distance between the points were selected along the area of interest and wear against distance was plotted FIGURE $\mathbf{2}$.

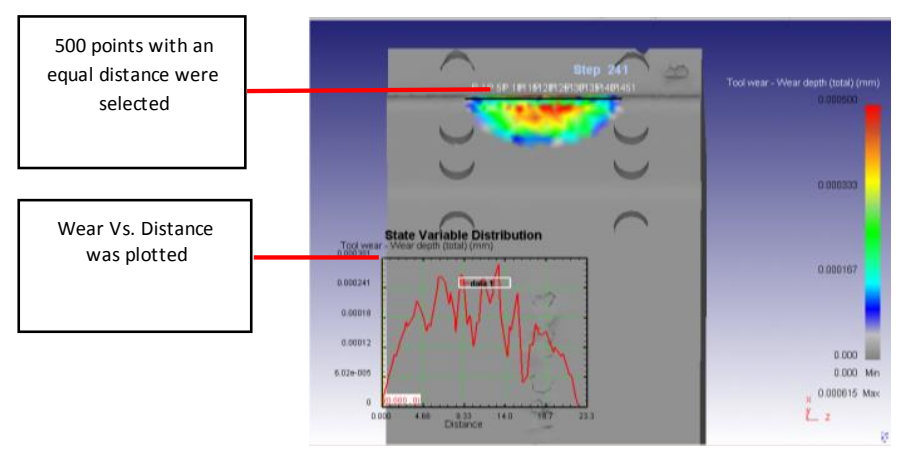

FIGURE 2. Simulation post-processor measurement method

For measuring tool wear, an Alicona Infinite Focus G4 Optical Microscope was used, which can produce a surface scan with repeatability of $1.2 \%$ according to type 1 repeatability study. It has a large range of different illumination sources, which makes the measurement of slope angles exceeding $80^{\circ}$ possible. The part was secured on a fixture which was placed on Alicona tray to reduce the vibration and increase the accuracy.

In a later stage, a MITUTOYO CRYSTA APEX C coordinate measurement machine (CMM) was used to scan the insert before and after the forging trial. For scanning using CMM, the insert was fixed to the CMM and manually aligned using the top, left and front surfaces. The alignment was repeated automatically three times. A scan line was then taken across the surface of the block. The scan was done using a SP25 probe and points were recorded every $0.05 \mathrm{~mm}$. Approximately 400 further scan lines were taken, with spacing between each line of $0.05 \mathrm{~mm}$. This generated a file containing the coordinates of approximately 290000 points, covering the a rea of interest on the part. The coordinates were then loaded into the GOM Inspect software to create a surface mesh. Then created surface could be compared before and after the forging trial.

\section{DISCUSSION AND RESULTS}

\section{Optical microscope analysis}

To analyse the surface which was scanned by the optical microscope, a plane was fitted to level the surface and everything above and below the plane was calculated. A cylindrical plane was fitted to measure the wear on the top part, which means cylinder diameter was considered as zero and the value above and below that was measured. A profile width of 10 (equivalent to $35.1472 \mu \mathrm{m}$ metric width) was used to measure abrasive wear on the top part of the insert shown on diagram A of FIGURE 3.

To measure adhesion on front face two rectangular planes were used on both side of the front face in order to level the surface. A profile width of 100 (equivalent $702.9443 \mu \mathrm{m}$ metric width) was used to measure the adhesion shown on diagram B FIGURE 3. 


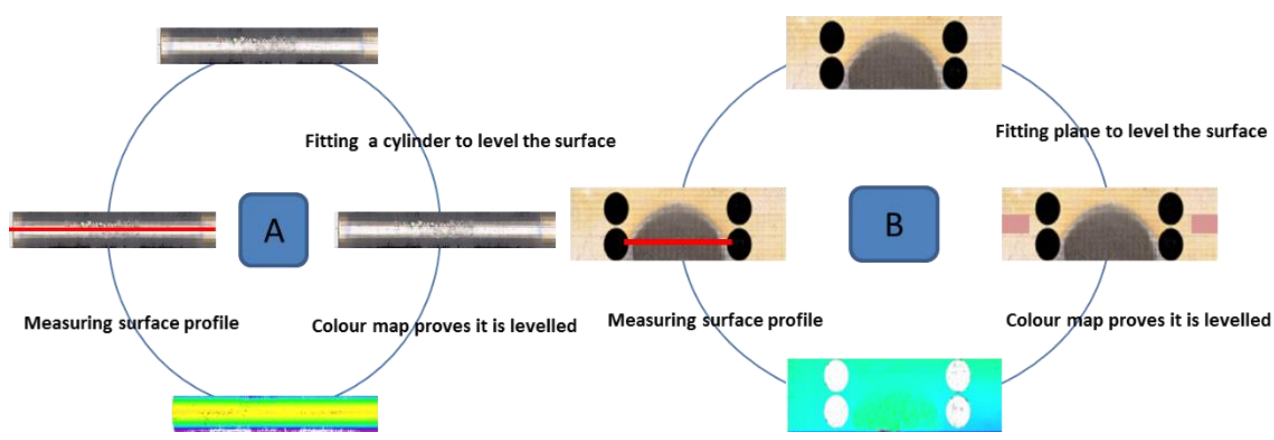

FIGURE 3. Diagram showing Optical Microscope analy sis for the top part of the insert A and for front face B

Optical microscope analysis showed a maximum abrasive wear depth of $29 \mu \mathrm{m}$ which correlates with $28.5 \mu \mathrm{m}$ abrasive wear results of the simulation. Fitted cylinder diameter of $3 \mathrm{~mm}$ was considered in calculating abrasive wear of $29 \mu \mathrm{m}$ by optical microscope's form module software shown on

FIGURE 4.

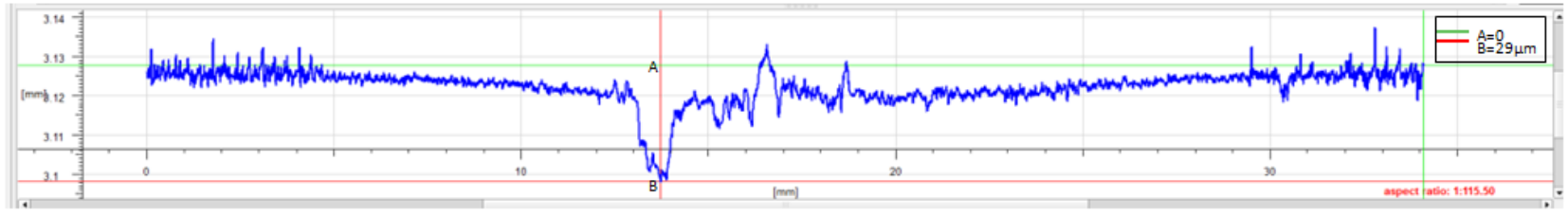

FIGURE 4. Optical Microscope surface profile shows $29 \mu \mathrm{m}$ of abrasive wear which is the distance between lines A and B.The optical microscope form module added the wear value to the diameter of fitted cylinder.

Optical microscope analysis showed a maximum adhesive wear of $17 \mu \mathrm{m}$, this value is the amount of adhesion above the fitted planes FIGURE 5.

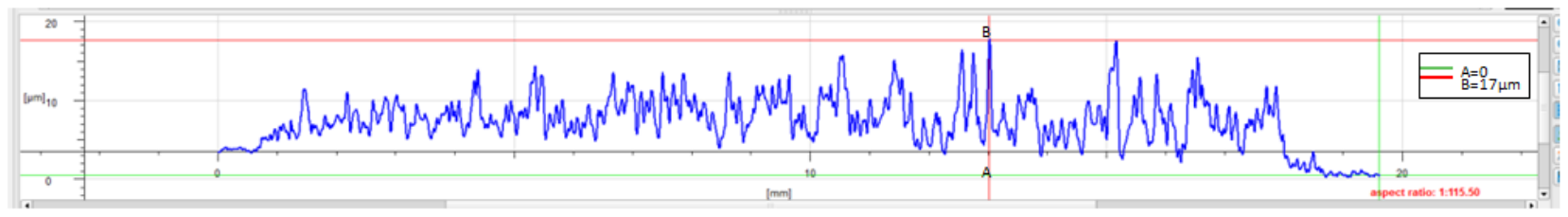

FIGURE 5. Optical Microscope surface profile shows $17 \mu \mathrm{m}$ of adhesive wear which is the distance between lines A and B.

\section{CMM Analysis}

After scanning the insert before and after the forging trial, it was overlaid using GOM software. The result shows $0.03 \mathrm{~mm}(30 \mu \mathrm{m})$ abrasion on the top part of the insert and $0.018 \mathrm{~mm}(18 \mu \mathrm{m})$ of adhesion on the front face of the insert, as shown in FIGURE 6. 


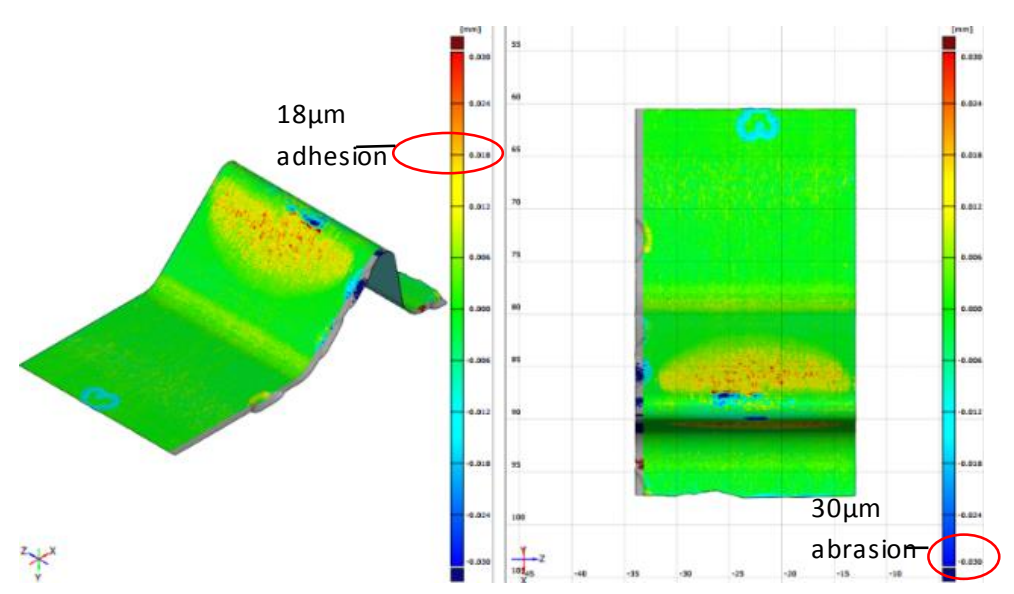

FIGURE 6. Overlaying surfaces scanned by CMM before and after the forging trial using GOM software $30 \mu \mathrm{m}$ of abrasive wear and $18 \mu \mathrm{m}$ of adhesion was observed.

\section{Thermal Camera Analysis}

Heat transfer between the work piece and die is one of the main factors affecting tools during the forging process, meaning that positioning the thermal camera as close as possible to the bolster can provide a relative temperature reading. Thermal Imaging Camera was therefore used to providereadings throughout the process. An emissivity of 0.7 was considered on the area not covered by graphite lubricant; the reading was then plotted for the location with maximum abrasive wear as shown on FIGURE 7.

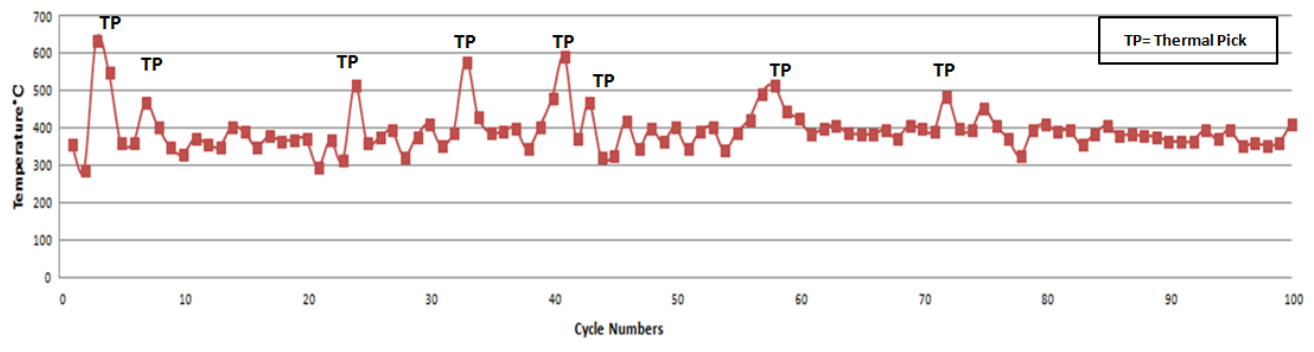

FIGURE 7.Thermal Camera readings for the selected point on the area with maximum wear on the insert which shows abnormal picks

\section{Multiple Cycle Simulation}

The simulation showed an expected wear of around $0.3 \mu \mathrm{m}$ per cycle. Multiple cycle simulation shows the linear progression FIGURE 8. This results proves that increasing load to some extent increases wear and using lubricant increases wear in open die forging [4]. The results also confirm that the $\mathrm{K}$ value of $1 \times 10^{-6}$ is suitable for this process condition.

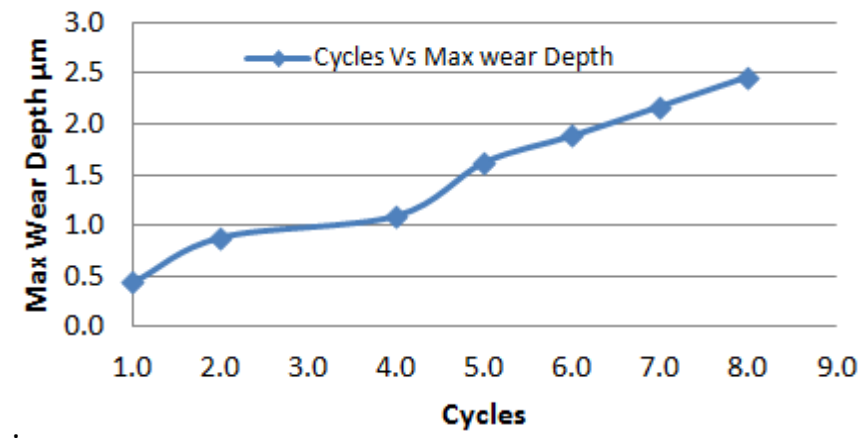

FIGURE 8.Multiple cycles simulation vs. Max wear depth 
The regression showed that the linear equation of (2) works well for this process as it shows $28.5 \mu \mathrm{m}$ (maximum abrasive wear) after 100 cycles which correlates with $29 \mu \mathrm{m}$ abrasive wear measurement on Optical Microscope after forging 100 billets.

$$
\text { Wear Depth }=0.1741+0.2833 \text { Cycles }
$$

\section{SUMMARY AND CONCLUSION}

Analysis of results shows a correlation between the simulation and the forging trial. The simulation predicted wear of around $0.3 \mu \mathrm{m}$ per cycle with a linear increment according to the result of regression. The regression predicted wear of around $28.5 \mu \mathrm{m}$ after 100 forging cycles which correlates with measured abrasive wear of $29 \mu \mathrm{m}$ on the Optical Microscope and abrasive wear of $30 \mu \mathrm{m}$ on CMM. Optical Microscope result showed adhesion of around 17 $\mu \mathrm{m}$ after 100 forging cycles, while the CMM result showed $18 \mu \mathrm{m}$ adhesion. The results show a close comparison between simulation and different method of measurements, however it has to be confirmed with further trials. The results from the thermal camera showed picks on certain forging cycles which indicate an increase in contact time on those cycles compared to the rest of the cycles. This thermal increment is because of an increase in contact time, which could be the cause of abrasive and adhesive wear in this trial. T. Altan mentions [13] that, in forging the metal flow, a non-steady state exists and contact between the deforming metal and the die is intermittent. The length of contact time and the nature of the heat transfer at the die and material interface therefore influences temperatures very significantly[13]. The results show that the proposed tool and experimental design can facilitate a cost effective method of tool wear analysis. This method can be used by industries to test different type of lubricants and coatings on industrial scale environment.

\section{REFERENCES}

1. [1] T. A. I, B. Lillg, and Y. C. Yen, "Manufacturing of Dies and Molds," 2000.

2. [2] J. a. A. Williams, "Wear modelling: analytical, computational and mapping: a continuum mechanics approach," Wear, vol. 225-229, pp. 1-17, 1999.

3. [3] S. Contents, D. Considerations, E. D. Halves, and C. Materials, "Tooling for Die Casting," pp. 1-22, and 2012.

4. [4] D. V. H. V. Colby Dahl, "Estimation of die wears in hot forging." III Confrencia international de for jamento (XX-SENAFOR) Journal Porto Brazil, 2000.

5. [5] R. Turk, I. Peruš, and M. Terčelj, "New starting points for the prediction of tool wear in hot forging," Int. J. Mach. Tools Manuf., vol. 44, no. 12-13, pp. 1319-1331, Oct. 2004.

6. [6] R. Tulsyan and R. Shivpuri, "Computer modeling of wear in extrusion and forging of automotive exhaust valves,” J. Mater. Eng. Perform. vol. 4, no. 2, pp. 161-165, Apr. 1995.

7. [7] H. C. Lee, Y. Lee, S. Y. Lee, S. Choi, D. L. Lee, and Y. T. Im, "Tool life prediction for the bolt forming process based on high-cycle fatigue and wear,” J. Mater. Process. Technol., vol. 201, no. 1-3, pp. 348-353, 2008.

8. [8] T. Materials, “The Materials Information Company,” Technology, vol. 2, p. 3470, 2001.

9. [9] G. Yong and D. Han, "Review of Applications of Vanadium in Steels," pp. 1-11, 2010.

10. [10]L. H. Chiu, C. F. Yang, W. C. Hsieh, and a. S. Cheng, "Effect of contact pressure on wear resistance of AISI H13 tool steels with chromium nitride and hard chromium coatings," Surf. Coatings Technol., vol. 154, no. 2-3, pp. 282-288, May 2002.

11. [11]Bharat Bhushan, Introduction to Tribology P-328, 2 Editions. 2013.

12. [12]S. Z. Qamar, a K. Sheikh, a F. M. Arif, T. Pervez, and R. a Siddiqui, "Heat treatment of a hot-work die steel," Arch. Mater. Sci. Eng., vol. 28, no. 8, pp. 503-508, 2007.

13. [13]T. Altan, G. Ngaile, and G. Shen, Cold and Hot Forging. 2004. 